\title{
Application on Online Process Learning Evaluation Based on Optimal Discrete Hopfield Neural Network and Entropy Weight TOPSIS Method
}

\author{
Chuanshuang Hu iD, ${ }^{1,2}$ Yongmei Ma, ${ }^{3}$ and Ting Chen ${ }^{4}{ }^{4}$ \\ ${ }^{1}$ School of Public Affairs, University of Science and Technology of China, Hefei 230026, China \\ ${ }^{2}$ Academic Affairs Office, Chaohu University, Chaohu 238000, China \\ ${ }^{3}$ Department of Mathematics and Statistics, Chaohu University, Chaohu 238000, China \\ ${ }^{4}$ School of Culture and Media, Anhui Xinhua University, Hefei 230088, China \\ Correspondence should be addressed to Ting Chen; chenting026@163.com
}

Received 1 May 2021; Accepted 26 May 2021; Published 8 June 2021

Academic Editor: Huihua Chen

Copyright (c) 2021 Chuanshuang Hu et al. This is an open access article distributed under the Creative Commons Attribution License, which permits unrestricted use, distribution, and reproduction in any medium, provided the original work is properly cited.

\begin{abstract}
Sustainable development education respects differences and encourages different assessment methods to evaluate students. During the epidemic, many colleges' examinations changed from offline to online. How to fully consider students' process learning status and make a reasonable evaluation of students is worthy of research. Based on the process learning data of a course in a university in China, this study establishes a discrete Hopfield neural network model to classify the test samples. In the process of modelling, the grey correlation analysis method is used to optimize the elements affecting students' comprehensive evaluation index, and it solves the problem of failure of the model due to the large gap between the factors in the traditional discrete Hopfield neural network model. Then, the entropy right TOPSIS method is used to rank samples with the same evaluation grade. Teachers can objectively evaluate each student's process learning performance according to the ranking results. Finally, the article compares and analyzes the evaluation results of various different methods. The analysis results believe that the optimized discrete Hopfield neural network is feasible in the process learning evaluation, and the model evaluation results are more objective and comprehensive.
\end{abstract}

\section{Introduction}

Education plays an important role in human beings. The United Nations General Assembly has advocated that governments should take sustainable development education as an education strategy and action plan. In recent years, many countries have incorporated the concept of sustainable development education into curricula, textbooks, and educational teaching practices and have been fruitful. Traditional curriculum learning evaluation tends to pay more attention to the result evaluation, ignoring the process evaluation and individual differences. Affected by the epidemic, China's education quickly moved from offline to online, so that teachers' "teaching" and students' "learning" have undergone unprecedented changes. Teachers and students mainly adopt online teaching and examination through the teaching platform, so how to integrate process learning evaluation and final examination evaluation and make an objective and fair evaluation of students is very worthy of study.

Process learning evaluation, also known as formative evaluation, is an immediate, dynamic, and repeated evaluation of students in the teaching process, which focuses on timely feedback to strengthen and improve students' learning [1]. The earliest introduction of procedural evaluation in Chinese universities was in college English classrooms. Yuan Shuhou and others believe that scholars' research perspectives are continuously integrated with 
disciplines, and the research content has evolved from procedural evaluation to dynamic instant evaluation [2]. After that, a process evaluation was also applied to different courses in science and engineering, humanities and social sciences, art and sports, and Chinese and Western medicine [3-6], but most of the research results are focused on qualitative analysis, especially, and less research on the classroom learning trajectory. In the process of online teaching, the mobile interactive teaching software effectively records the dynamics of students' course learning. This significantly reduces the usual statistical work and makes the data collection of process evaluation easier. Therefore, it is feasible to evaluate students' process learning quantitatively by establishing a mathematical model. It is the inevitable way of the development of the times to assess students from a single final examination result evaluation to process learning evaluation. Process learning evaluation can objectively, multifacetedly, and multidimensionally reflect the status of students in the learning process, so the research process learning evaluation model has certain research significance.

Hopfield neural network is a recurrent neural network, proposed by J. Hopfield in 1982. The discrete Hopfield neural network in Hopfield neural network is named DHNN (discrete Hopfield neural network). It is a singlelayer feedback neural network with feedback connection from output to input; it is also a kind of cyclic neural network [7]. Associative memory function is an important application of discrete Hopfield neural networks. In recent years, more and more researchers try to use discrete Hopfield neural network for recognition and evaluation, such as disease diagnosis $[8,9]$, license plate recognition [10], water quality evaluation $[11,12]$, risk assessment $[13$, $14]$, comprehensive evaluation $[15,16]$, and disaster assessment [17].

In discrete Hopfield neural networks, some optimization algorithms are often combined with discrete Hopfield neural networks in order to make them more capable of association with memory. The improved method has a heuristic effect on other complex recurrent neural networks. Many scholars have changed the network structure, improved the weight design algorithm $[18,19]$, and set the delay and other methods to make the recurrent neural network have stronger associative memory ability [20]. Besides, the genetic algorithm is applied to a discrete Hopfield neural network to make the network stable. In some evaluation model studies, it is found that the traditional discrete Hopfield neural network model is not applicable when the gap between the factors affected is relatively large. In this study, we try to change the structure of the original neural network by using the method of grey relational analysis, taking the sample of the Hopfield neural network which cannot find the closest equilibrium point, and by establishing a new network structure and an ideal evaluation grade, the problem of samples which cannot be classified normally can be solved.

\section{Materials and Methods}

Affected by the epidemic, in the first half of 2020, Chinese universities mainly use online teaching and examination: how to integrate process evaluation and final examination evaluation organically and give students fair, objective, and reasonable evaluation is necessary. In this context, if teachers still take students' final examination results as the evaluation standard of students' learning this course, it is clear that the evaluation results are not objective enough. The development process from quantity change to qualitative change is long, and learning evaluation is a dynamic process. Therefore, this research takes the process assessment of college students' curriculum learning as the research content, through the analysis of students' dynamic learning process state, using qualitative and quantitative analysis methods, and it establishes an effective evaluation model and gives an objective and fair evaluation.

This study took 49 students in the second year of a university as the research object, and the research data came from the learning process data of the "Education theory" course in the background of mobile interactive teaching software (xue-xi-tong APP) (time: the second semester of the 2019-2020 academic year). For the first time, 6 indicators were selected, and the initial classification level was given by the comprehensive evaluation score of learning software, as shown in Table 1.

\section{Research Method}

3.1. Construction of the Discrete Hopfield Neural Network Model. Suppose the output value of DHNN is -1 or 1 , which are recorded as the inhibition and excitation states of neurons, respectively. The given marks are as follows:

(1) $x_{i}$ is an external input value.

(2) $b_{i}(t)$ is a threshold of the $i$ th neuron.

(3) $\omega_{i j}$ is the connection weight between any two neurons, $\omega_{i j}=\omega_{j i}$.

(4) $u_{j}$ is a binary neuron, $u_{j}=\sum_{i} \omega_{i j} y_{i}+x_{j}$.

(5) $y_{i}$ is an output value, $y_{i}=\left\{\begin{array}{ll}-1 & u_{j}<b_{i} \\ 1 & u_{j} \geq b_{i}\end{array}\right.$.

(6) $y_{j}(t)$ is the $j$ neuron and indicates the state of node jth at time $t$.

$y_{j}(t+1)$ is the state of node jth at time $t+1$ :

$$
y_{j}(t+1)=f\left[u_{j}(t)\right]=\left\{\begin{array}{ll}
-1, & u_{j}(t)<0 \\
1, & u_{j}(t) \geq 0
\end{array}, \quad f\right. \text { is a nonlinear function. }
$$


TABLE 1: The dynamic learning process ability level and the corresponding evaluation index of 49 students.

\begin{tabular}{|c|c|c|c|c|c|c|c|}
\hline Number & $\begin{array}{c}\text { Watching } \\
\text { audio and video } X_{1}\end{array}$ & $\begin{array}{c}\text { Times of } \\
\text { chapter learning } X_{2}\end{array}$ & $\begin{array}{c}\text { Score for } \\
\text { homework } X_{3}\end{array}$ & $\begin{array}{l}\text { Score for unit } \\
\text { test } X_{4}\end{array}$ & $\begin{array}{c}\text { Score for } \\
\text { group } \\
\text { task } X_{5}\end{array}$ & $\begin{array}{c}\text { Course } \\
\text { interaction } X_{6}\end{array}$ & Grade (ABCDE) \\
\hline 1 & 100.0 & 100.0 & 95.0 & 73.5 & 92.7 & 90.0 & A \\
\hline 2 & 95.4 & 100.0 & 94.0 & 84.1 & 93.3 & 100.0 & $\mathrm{~A}$ \\
\hline 3 & 100.0 & 100.0 & 98.2 & 75.8 & 90.0 & 100.0 & $\mathrm{~A}$ \\
\hline 4 & 71.6 & 100.0 & 97.2 & 88.6 & 90.0 & 100.0 & $\mathrm{~A}$ \\
\hline 5 & 96.2 & 89.0 & 95.9 & 71.2 & 90.0 & 89.0 & B \\
\hline 6 & 74.0 & 90.0 & 92.6 & 73.5 & 92.7 & 90.0 & $\mathrm{~B}$ \\
\hline 7 & 96.0 & 92.0 & 95.6 & 71.2 & 73.3 & 94.0 & B \\
\hline 8 & 71.6 & 91.0 & 99.0 & 71.2 & 71.7 & 88.0 & $\mathrm{~B}$ \\
\hline 9 & 74.5 & 92.0 & 96.9 & 84.1 & 73.3 & 90.0 & B \\
\hline 10 & 70.8 & 42.4 & 86.3 & 84.1 & 86.7 & 91.0 & B \\
\hline 11 & 74.0 & 92.0 & 91.0 & 79.5 & 73.3 & 92.5 & B \\
\hline 12 & 73.0 & 97.6 & 91.7 & 65.2 & 92.7 & 78.0 & B \\
\hline 13 & 72.0 & 86.6 & 96.6 & 71.2 & 71.7 & 92.5 & B \\
\hline 14 & 73.4 & 74.2 & 82.7 & 77.3 & 81.7 & 65.0 & $\mathrm{C}$ \\
\hline 15 & 74.0 & 100.0 & 92.6 & 84.1 & 61.0 & 89.0 & $\mathrm{C}$ \\
\hline 16 & 70.8 & 43.4 & 95.4 & 18.2 & 90.0 & 100.0 & $\mathrm{C}$ \\
\hline 17 & 72.0 & 38.4 & 89.8 & 71.2 & 85.0 & 82.5 & $\mathrm{C}$ \\
\hline 18 & 76.0 & 47.6 & 91.0 & 76.5 & 87.7 & 92.5 & $\mathrm{C}$ \\
\hline 19 & 71.0 & 100.0 & 91.8 & 84.1 & 61.0 & 90.0 & $\mathrm{C}$ \\
\hline 20 & 73.4 & 68.8 & 83.1 & 75.8 & 90.0 & 72.5 & $\mathrm{C}$ \\
\hline 21 & 71.0 & 53.4 & 80.8 & 79.5 & 72.7 & 75.0 & $\mathrm{C}$ \\
\hline 22 & 70.8 & 35.0 & 89.9 & 84.1 & 73.3 & 80.0 & $\mathrm{C}$ \\
\hline 23 & 75.0 & 68.8 & 88.8 & 84.1 & 86.7 & 77.5 & $\mathrm{C}$ \\
\hline 24 & 71.0 & 100.0 & 91.3 & 79.5 & 61.0 & 100.0 & $\mathrm{C}$ \\
\hline 25 & 72.0 & 50.0 & 91.3 & 84.1 & 72.7 & 82.5 & C \\
\hline 26 & 72.0 & 71.0 & 97.0 & 79.5 & 71.7 & 62.5 & C \\
\hline 27 & 72.0 & 100.0 & 85.8 & 79.5 & 86.3 & 62.5 & $\mathrm{C}$ \\
\hline 28 & 72.0 & 91.6 & 95.7 & 68.9 & 80.0 & 57.5 & $\mathrm{C}$ \\
\hline 29 & 70.0 & 95.0 & 88.7 & 33.3 & 73.3 & 95.0 & $\mathrm{C}$ \\
\hline 30 & 70.8 & 100.0 & 94.8 & 71.2 & 56.7 & 90.0 & C \\
\hline 31 & 73.4 & 70.8 & 93.8 & 67.4 & 71.7 & 77.5 & $\mathrm{C}$ \\
\hline 32 & 73.0 & 38.4 & 92.1 & 75.8 & 71.7 & 82.0 & $\mathrm{C}$ \\
\hline 33 & 70.8 & 26.6 & 86.0 & 84.1 & 91.7 & 52.0 & C \\
\hline 34 & 72.3 & 100.0 & 82.7 & 75.8 & 73.3 & 67.5 & $\mathrm{C}$ \\
\hline 35 & 74.2 & 34.2 & 85.6 & 84.1 & 73.3 & 82.0 & $\mathrm{C}$ \\
\hline 36 & 90.0 & 89.2 & 92.9 & 93.2 & 77.7 & 40.0 & C \\
\hline 37 & 73.0 & 100.0 & 84.5 & 79.5 & 66.7 & 60.0 & C \\
\hline 38 & 72.0 & 59.2 & 95.0 & 61.4 & 70.3 & 72.5 & C \\
\hline 39 & 74.2 & 65.0 & 87.9 & 81.1 & 76.0 & 65.0 & $\mathrm{C}$ \\
\hline 40 & 72.0 & 29.2 & 81.0 & 77.3 & 78.3 & 85.5 & $\mathrm{C}$ \\
\hline 41 & 70.8 & 60.0 & 70.0 & 84.1 & 73.3 & 58.0 & $\mathrm{C}$ \\
\hline 42 & 72.0 & 25.8 & 85.2 & 33.3 & 73.3 & 95.0 & $\mathrm{C}$ \\
\hline 43 & 76.8 & 80.8 & 86.3 & 68.9 & 70.3 & 65.0 & $\mathrm{C}$ \\
\hline 44 & 74.2 & 92.4 & 73.3 & 71.2 & 65.0 & 35.0 & $\mathrm{D}$ \\
\hline 45 & 70.8 & 48.4 & 84.3 & 56.1 & 63.3 & 67.5 & $\mathrm{D}$ \\
\hline 46 & 73.4 & 83.4 & 86.6 & 71.2 & 57.7 & 55.0 & $\mathrm{D}$ \\
\hline 47 & 70.4 & 75.0 & 74.7 & 75.8 & 76.7 & 57.5 & $\mathrm{D}$ \\
\hline 48 & 70.8 & 15.0 & 75.7 & 71.2 & 74.3 & 57.5 & $\mathrm{D}$ \\
\hline 49 & 70.0 & 17.6 & 36.0 & 41.7 & 63.3 & 22.5 & $\mathrm{E}$ \\
\hline
\end{tabular}


(7) $Y(t)=\left[y_{1}(t), y_{2}(t), \ldots, y_{n}(t)\right]$ is an $n$-dimensional vector.

3.1.1. Network Architecture. The initial structure of the DHNN is composed of six neurons, as shown in Figure 1.

3.1.2. Network Working Mode. Set the working mode of the Hopfield network to serial mode. It is assumed that the working network is stable. The rule of evolution is to decrease the energy function until it reaches a stable state. The Lyapunov function here is the energy function, and it is defined as follows:

$$
E=-\frac{1}{2} \sum_{i=1}^{N} \sum_{j=1}^{N} \omega_{i j} y_{i} y_{j}-\sum_{i=1}^{N} b_{i} y_{i}
$$

In this model, the outer-product method is used to design the Hopfield network, and the training goal preserves $\mathrm{K} n$-dimensional attractors:

$$
\begin{aligned}
& C^{k}=\left[c_{1}^{k}, c_{2}^{k}, \ldots, c_{n}^{k}\right], \\
& \omega_{i j}= \begin{cases}\frac{1}{a} \sum_{k=1}^{K} c_{i}^{k} c_{j}^{k}, & i, j=1,2, \ldots, n, \\
0, & i=j,\end{cases}
\end{aligned}
$$

where $a$ is the adjusting ratio; take $a=n$.

The operation steps are as follows:

Step 1: initialize the network.

Step 2: the ith neuron is randomly selected from the network.

Step 3: calculate the input value $u_{i}(t)$ for the ith neuron. Step 4: calculate the output value $v_{i}(t+1)$ for the ith neuron. At this time, the output of other neurons in the network remains unchanged.

Step 5: to determine whether the network is stable or not: if it is stable or meets the given conditions, it ends; otherwise, go to step 2 and continue. $\Delta t>0$.

The steady state here is defined as $v(t+\Delta t)=v(t)$,

\subsection{Design of the Initial Discrete Hopfield Neural Network Model}

(1) The ideal grade evaluation index is designed.

The average of the evaluation indicators corresponding to the samples in Table 1 is used as the ideal evaluation indicator for each level, that is, as the equilibrium point of the Hopfield neural network, as shown in Table 2.

(2) The ideal grade evaluation index is coded.

As shown in the first line of Figure 2, "๑" indicates that the state of the neuron is " 1 ", which is greater

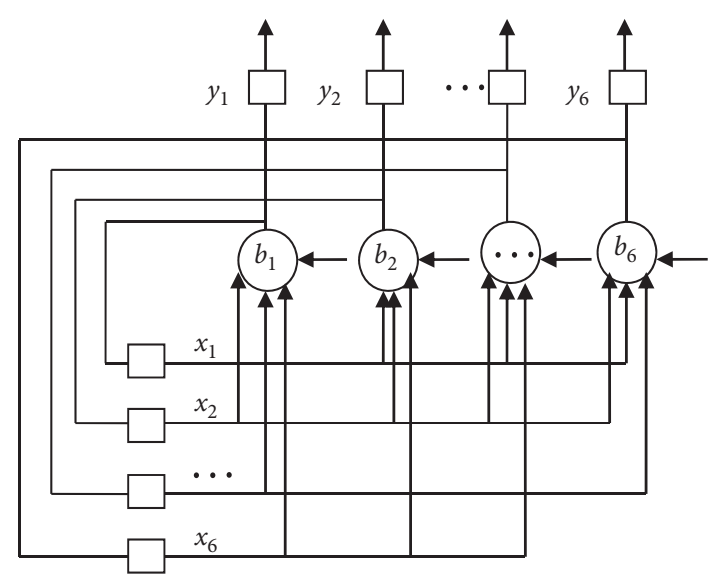

FIGURE 1: Structure diagram of discrete Hopfield network.

TABLE 2: Five-grade ideal evaluation indexes.

\begin{tabular}{lcccccc}
\hline \multirow{2}{*}{ Grade } & $X_{1}$ & $X_{2}$ & $X_{3}$ & $X_{4}$ & $X_{5}$ & $X_{6}$ \\
\hline A & 91.8 & 100 & 96.1 & 80.5 & 91.5 & 97.5 \\
B & 78 & 85.8 & 95.4 & 74.6 & 80.6 & 89.1 \\
C & 73.1 & 65.9 & 88.5 & 72.8 & 75.3 & 77.7 \\
D & 71.9 & 62.8 & 82.9 & 68.6 & 69.4 & 54.5 \\
E & 70 & 17.6 & 36 & 41.7 & 63.3 & 22.5 \\
\hline
\end{tabular}

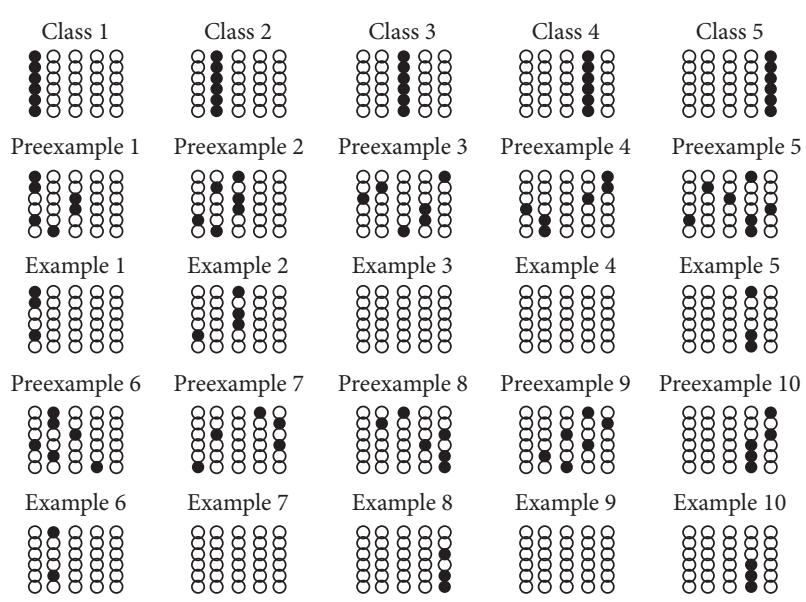

FIgURE 2: Simulation results of grade evaluation for 10 test samples.

than or equal to the ideal evaluation index value of the corresponding grade; otherwise, it is expressed by “O."

(3) The test sample index is coded.

Select ten samples from Table 1 as test samples. The corresponding values are shown in Table 3 . The corresponding coding is obtained according to the above coding rules, as shown in the second line of Figure 2.

(4) MATLAB is used to create the discrete Hopfield neural network.

(5) The simulation results are in Figure 2. 
TABLe 3: Evaluation index values of 10 test samples.

\begin{tabular}{|c|c|c|c|c|c|c|c|c|}
\hline Original serial number & New serial number & $X_{1}$ & $X_{2}$ & $X_{3}$ & $X_{4}$ & $X_{5}$ & $X_{6}$ & Grade \\
\hline 1 & Example 1 & 100.0 & 100.0 & 95.0 & 73.5 & 92.7 & 90.0 & $\mathrm{~A}$ \\
\hline 6 & Example 2 & 74.0 & 90.0 & 92.6 & 73.5 & 92.7 & 90.0 & B \\
\hline 8 & Example 3 & 71.6 & 91.0 & 99.0 & 71.2 & 71.7 & 88.0 & $\mathrm{~B}$ \\
\hline 10 & Example 4 & 70.8 & 42.4 & 86.3 & 84.1 & 86.7 & 91.0 & B \\
\hline 12 & Example 5 & 73.0 & 97.6 & 91.7 & 65.2 & 92.7 & 78.0 & $\mathrm{~B}$ \\
\hline 36 & Example 6 & 90.0 & 89.2 & 92.9 & 93.2 & 77.7 & 40.0 & $\mathrm{C}$ \\
\hline 43 & Example 7 & 72.0 & 25.8 & 85.2 & 33.3 & 73.3 & 95.0 & $\mathrm{C}$ \\
\hline 44 & Example 8 & 74.2 & 92.4 & 73.3 & 71.2 & 65.0 & 35.0 & $\mathrm{D}$ \\
\hline 48 & Example 9 & 70.8 & 15.0 & 75.7 & 71.2 & 74.3 & 57.5 & $\mathrm{D}$ \\
\hline 17 & Example 10 & 72.0 & 38.4 & 89.8 & 71.2 & 85.0 & 82.5 & $\mathrm{C}$ \\
\hline
\end{tabular}

As seen from Figure 2, the 10 students to be classified were not properly classified. The reason for the incorrect classification is that there is a big difference in the values of various factors, and the closest equilibrium point cannot be found in the Hopfield neural network. Next, we will look for a new way to solve the problem.

\subsection{Reconstruction of Hopfield Neural Network Structure by} Grey Relational Analysis. The basic idea of grey relational analysis is to judge whether the relation is close or not according to the geometric shape similarity of the sequence curve. The closer the curves are, the greater the correlation between the corresponding sequences is. The steps of grey correlation analysis are as follows:

Step 1: determine the system analysis sequence.

The reference sequence is denoted as

$$
X_{0}=\left(x_{0}(1), x_{0}(2), \ldots, x_{0}(5)\right)=(93.7,86,74.6,64,462) \text {. }
$$

Comparison sequence (also known as subsequence) is an effective factor affecting the main behavior of the system. There are six effective factors here. The behavior sequence of factor $i$ is $X_{i}=\left(x_{i}(1), x_{i}(2)\right.$, $\left.\ldots, x_{i}(5)\right), i=1,2, \ldots, 6$.

Step 2: the dimensionless treatment of variables.

Because of the different scale of the data affecting the various factors of the comprehensive evaluation, in order to facilitate comparison, it is necessary to carry out the nonscale processing $X_{i}^{0}=\left(\begin{array}{ll}x_{i} & (1)-x_{i}\end{array}\right.$ $\left.(1), \ldots, x_{i}(k)-x_{i}(1), \ldots, x_{i}(5)-x_{i}(1)\right) ; i=1, \ldots$, $6, k=1,2, \ldots, 5$.

Step 3: calculate the comprehensive correlation degree $[21,22]$ :

$$
\begin{aligned}
& \rho_{0 i}=\theta \cdot \varepsilon_{0 i}+(1-\theta) r_{0 i} ; \quad i=1, \ldots, 6 \\
& \rho_{01}=0.6 \\
& \rho_{02}=0.9 \\
& \rho_{03}=0.7 \\
& \rho_{04}=0.7 \\
& \rho_{05}=0.7 \\
& \rho_{06}=0.9 .
\end{aligned}
$$

Grey system modelling software can also be used here (software downloads address: http://igss.nuaa.edu.cn/ main.htm).

Step 4: build a new evaluation index.

Evaluating Indicator $Y_{1}$ is defined as the index of selfdiscipline ability. It reflects students' ability of autonomous learning after class, and its value is obtained by weighting $X_{1}$ and $X_{2}$ according to the grey correlation degree.

Evaluating Indicator $Y_{2}$ is defined as the index of practical ability. It reflects the students' ability to use the knowledge to solve problems, and its value is obtained by weighting $X_{3}, X_{4}$, and $X_{5}$ according to the grey correlation degree.

Evaluating Indicator $Y_{3}$ is defined as the index of classroom interaction ability. It reflects the students' participation in answering questions, participating in discussions, raising hands, and other activities in class. This index value corresponds to the value of $X_{6}$.

Put it all together and fill in Table 4.

Step 5: construct a new ideal classification index hierarchy.

According to the value of each case in Table 4, combined with the score of the entire class, we give the adjusted new ideal classification index level, as shown in Table 5.

Repeating the steps in 2.2.3, the ideal grade evaluation index and waiting classification index is coded again. Running MATLAB code, the simulation results are organized as shown in Figure 3.

It can be seen from Figure 3 that the reconstructed discrete Hopfield neural network model can correctly classify 10 test samples, and the classification level is shown in the first row of this figure.

3.4. Classification Results Are Sorted by Entropy Weight TOPSIS Method [23, 24]. As can be seen from Figure 3, the 10 test students are rated as B, C, D, and E, respectively. None of the students reached grade A. If you give scores to students of the same level, how many points should each student score? In order to objectively evaluate, the entropy TOPSIS method is selected here. By calculating the entropy weight of each indicator and fully considering the effect of entropy weight, each test sample is further rationally sorted. 
TABLE 4: Evaluation index values of 10 test samples.

\begin{tabular}{lccc}
\hline New serial number & $Y_{1}$ & $Y_{2}$ & $Y_{3}$ \\
\hline Example 1 & 100 & 87.1 & 90 \\
Example 2 & 83.6 & 86.3 & 90 \\
Example 3 & 83.2 & 80.6 & 88 \\
Example 4 & 53.8 & 85.4 & 91 \\
Example 5 & 87.8 & 79 & 78 \\
Example 6 & 89.5 & 87.9 & 40 \\
Example 7 & 44.3 & 63.9 & 95 \\
Example 8 & 85.1 & 69.8 & 35 \\
Example 9 & 37.3 & 75 & 57.5 \\
Example 10 & 51.8 & 82 & 82.5 \\
\hline
\end{tabular}

TABLE 5: Adjusted ideal grade evaluation index.

\begin{tabular}{lccc}
\hline Grade & \multicolumn{3}{c}{ Index } \\
& $Y_{1}$ & $Y_{2}$ & $Y_{3}$ \\
\hline A & 96.7 & 89.4 & 97.5 \\
B & 82.7 & 83.5 & 89.1 \\
C & 69.6 & 78.8 & 77.7 \\
D & 67.2 & 74.1 & 54.5 \\
E & 38.6 & 47 & 22.5 \\
\hline
\end{tabular}

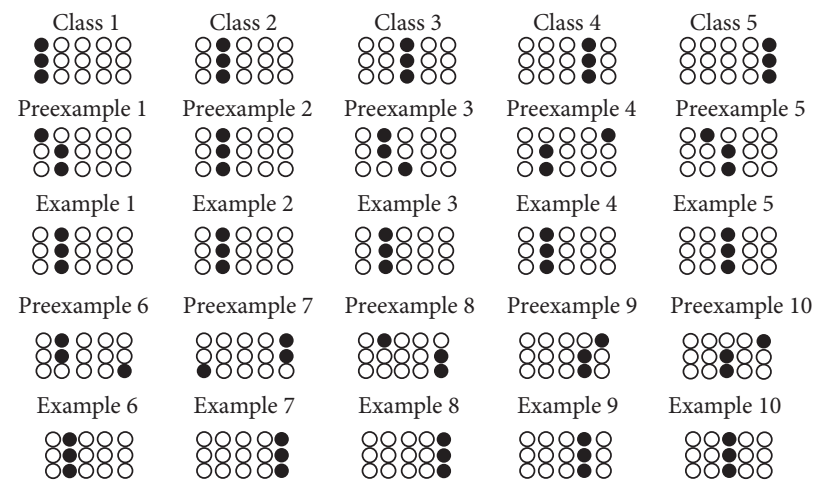

Figure 3: Classification simulation results of the reconstructed discrete Hopfield neural network.

There are 10 students to be evaluated and three evaluation indicators, so the original data matrix is constructed as

$$
B=\left(b_{i j}\right)_{10 \times 3}=\left(\begin{array}{ccc}
b_{11} & b_{12} & b_{13} \\
\vdots & \vdots & \vdots \\
b_{101} & b_{102} & b_{103}
\end{array}\right), \quad i=1, \ldots, 10, j=1,2,3
$$

where $b_{i j}$ indicates the value of the $j$ th indicator corresponding to the $i$ th student. The specific values are shown in Table 4.

According to the formula of entropy weight TOPSIS, the final result is obtained:

$$
C_{i}=\frac{d_{i}^{-}}{d_{i}^{+}+d_{i}^{-}} \times 100, \quad i=1,2, \ldots, 10,
$$

with 


$$
\begin{aligned}
p_{i j} & =\frac{c_{i j}}{\sum_{i=1}^{10} c_{i j}}, \\
w_{j} & =\frac{\left(1-e_{j}\right)}{\sum_{j=1}^{3}\left(1-e_{j}\right)}, \\
e_{j} & =-\frac{1}{\ln 10} \sum_{i=1}^{10} p_{i j} \cdot \ln p_{i j}, \\
c_{i j} & =\frac{b_{i j}-b_{\min (j)}}{b_{\max (j)}-b_{\min (j)}} \times \theta+(1-\theta), \quad \theta=0.9, \\
b_{\min (j)} & =\min _{i}\left\{b_{i j}\right\}, b_{\max (j)}=\max _{i}\left\{b_{i j}\right\}, \\
H & =\left(h_{i j}\right)_{10 \times 3}=\left(w_{j} c_{i j}\right)_{10 \times 3}, \\
d_{i}^{+} & =\sum_{j=1}^{3} h_{j}^{+}-\sum_{j=1}^{3} h_{i j}, \quad(i=1,2, \ldots, 10),\left\{h_{j}^{+}, j=1,2,3\right\}=\left\{\max _{i} h_{i j}, j=1,2,3\right\}, \\
d_{i}^{-} & =\sum_{j=1}^{3} h_{i j}-\sum_{j=1}^{3} h_{j}^{-} \quad(i=1,2, \ldots, 10),\left\{h_{j}^{-}, j=1,2,3\right\}=\left\{\min _{i} h_{i j}, j=1,2,3\right\} .
\end{aligned}
$$

\section{Result Analysis}

The results are summarized in Table 6 .

It can be seen from Table 6 that there are some differences in the evaluation results of 10 students to be classified under different evaluation methods; especially, the classification grade of the final examination and the classification results of the other two methods are quite different. The following is based on the optimized discrete Hopfield neural network level results to analyze the evaluation results of students' process learning.

Grade A: no student has reached this level.

Grade B: Students 1, 6, 8, 10, and 36. In the final examination papers, students numbers 6 and 8 are rated as A level, which is also the result of teachers' evaluation of students in the traditional assessment. However, a careful analysis of the usual learning status of the three students revealed that everyone's process learning performance was not very good. Students 6 and 8 were fine overall, but they did not score above 90 on various measures, so it was reasonable to classify them as B grades.

In the three different evaluation methods, the evaluation level of the number 10 student is consistent. It shows that the student is at a good level no matter the kind of evaluation method. Because the student usually has good study habits, the examination results are also ideal.

Number 1 student usually studies very seriously; especially, their self-discipline ability is better. But this students' application ability and classroom interaction ability is a little poor, which is consistent with his final grade.

Although the test score of number 36 student belongs to $\mathrm{D}$ level, the self-discipline ability and practical ability of this student are relatively good, so it is classified as B level. At the same time, we found that he had less interaction with the teacher in class, indicating that the student was shy and not good at expressing himself, so he should pay more attention to the classmate in the future.

Grade C: Students 12 and 17. Student number 12 is classified as $\mathrm{C}$ grade because of the middle level of homework, task completion, unit test scores, and classroom interaction, which is one level higher than the student's final grade, indicating that the student did not perform well in the exam.

Although the final result of student number 17 was very good, his attitude towards learning was slow. He had a low score for watching videos and completing task points, and he did not cooperate with the teacher in the learning process. In future, the teacher should deeply understand the needs of students, timely adjust the way of class, and let all students participate in the course learning. On the other hand, the student's final exam results are questionable, and we may need to know more about the student's learning of other subjects and other students' evaluation of him.

Grade D: Student 48. The classification level of number 48 student is consistent with the initial level. According to the score data, the self-discipline ability of the student is very poor. The completion of the course tasks 
TABLE 6: Comparative analysis table of evaluation results of 10 students to be classified.

\begin{tabular}{|c|c|c|c|c|c|c|}
\hline $\begin{array}{l}\text { Original serial } \\
\text { number }\end{array}$ & $\begin{array}{c}\text { Initial classification } \\
\text { level }\end{array}$ & $\begin{array}{l}\text { Grading by optimized } \\
\text { neural network }\end{array}$ & $\begin{array}{c}\text { Score of } \\
\text { entropy weight } \\
\text { TOPSIS Ci }\end{array}$ & $\begin{array}{c}\text { Ranking of } \\
\text { entropy weight } \\
\text { TOPSIS } \\
\end{array}$ & $\begin{array}{l}\text { Final exam } \\
\text { results }\end{array}$ & $\begin{array}{l}\text { Grading by final } \\
\text { exam }\end{array}$ \\
\hline 1 & $\mathrm{~A}$ & B & 98.17 & 1 & 86.0 & B \\
\hline 6 & B & B & 86.76 & 2 & 90.0 & A \\
\hline 8 & B & B & 78.66 & 3 & 94.0 & A \\
\hline 10 & B & B & 67.6 & 4 & 88.0 & B \\
\hline 36 & B & B & 60.66 & 5 & 66.0 & $\mathrm{D}$ \\
\hline 12 & C & C & 73.03 & 1 & 66.0 & $\mathrm{D}$ \\
\hline 17 & C & $\mathrm{C}$ & 56.72 & 2 & 96.0 & A \\
\hline 48 & $\mathrm{D}$ & $\mathrm{D}$ & 23.44 & 1 & 50.0 & $\mathrm{E}$ \\
\hline 43 & $\mathrm{C}$ & $\mathrm{E}$ & 38.28 & 1 & 50.0 & $\mathrm{E}$ \\
\hline 44 & $\mathrm{D}$ & E & 32.91 & 2 & 60.0 & $\mathrm{D}$ \\
\hline
\end{tabular}

assigned by the teacher is average. The interactive ability in class and the practical ability after class are at level $\mathrm{D}$. Therefore, it is directly related to the examination score below 60 points, which indicates that the usual learning attitude is positively related to the final examination score.

Grade E: Students 43 and 44. Numbers 43 and 44 students are classified as grade E. After a careful analysis of these two students, it was found that although number 43 student was very active in class, he had a poor attitude towards learning after class, which indicated that he was a typical student with poor selfdiscipline and needed to be supervised and managed by the teacher. Although student number 44 studied conscientiously at ordinary times, his proficiency in knowledge was not good enough to apply what he had learned into practice. In addition, he was not active in class and was not good at communicating and learning with teachers, which ultimately led to his unsatisfactory final score.

In addition, the entropy weight TOPSIS method gives the same level of student ranking, which provides a strong reference for students' usual scores. For example, there are five students in class B. According to the entropy weight TOPSIS score column in Table 6 , it can be seen that the student with the highest score is number 1 , the student with the lowest score is number 36 , followed by numbers 6,8 , and 10 in the middle. Therefore, teachers can refer to this ranking when giving scores to ordinary students.

Through the above analysis, the following conclusions are drawn:

Conclusion 1: reasonable process learning evaluation method can objectively evaluate students' normal performance justly, dynamically grasp students' normal learning state, analyze students' learning characteristics from students' learning state, and provide valuable help to students targeted.

Conclusion 2: the optimized discrete Hopfield neural network model is effective in the process learning evaluation. Through the grey correlation analysis among various factors, the weighted processing of impact evaluation indexes according to the correlation degree can achieve the goal of model optimization. In particular, it solves the problem that the traditional discrete Hopfield neural network model fails to find the equilibrium point due to the large gap between factors.

Conclusion 3: the method of entropy weight TOPSIS can objectively give the order of the samples with the same level, which provides a good reference for the given results of teachers in peacetime.

Education is a major force for sustainable development and change and for improving people's ability to transform social ideals into reality. Education for sustainable development has been seen as a process of learning how to make decisions that take into account economic, ecological, and all social equity. Cultivating this future-oriented thinking ability is a key task of education. This paper has established that sustainable development education has built up students' dominant position in the teaching process. Especially in the online teaching background, students' self-discipline, practical ability, and classroom interaction ability have been fully reflected. The dynamic process learning evaluation model combined with the three evaluation indexes gives the evaluation results of students' daily learning objectively and comprehensively. This result is helpful to do a good job of education and teaching and to provide reference and guidance for students' education management.

\section{Data Availability}

The data used to support the findings of this study are available from the authors upon request.

\section{Conflicts of Interest}

The authors declare that they have no conflicts of interest.

\section{Authors' Contributions}

C. S., Y. M., and T. C. were responsible for conceptualization; Y. M. prepared methodology; Y. M. curated data; C. S., Y. M., and T. C. wrote the original draft; C. S. and Y. M. carried out 
review and editing; Y. M., C. S., and T. C. performed visualization; and C. S. and T. C supervised the data.

\section{Acknowledgments}

The authors acknowledge the Research Project of Humanities and Social Sciences in Colleges and Universities of Anhui Province (SK2019A0545); Online Important Teaching Research Project of Anhui Province Colleges and Universities (2020zdxsjg234); Anhui Quality Engineering Project (2018mooc508 and 2019mooc273); and Teaching Team Project of Chaohu University (ch20jxtd02).

\section{References}

[1] D. Zhao, "Program development and the role of evaluation," Formative Evaluation for Educational Technologies, vol. 3, pp. 47-62, 2013.

[2] J. Zhang and M. Li, "How does process learning evaluation affect college students' learning engagement and learning effect -- data analysis based on "H University undergraduate learning and development survey"," Research in Higher Education of Engineering, vol. 6, pp. 119-124, 2015.

[3] X. Zhang, R. Li, H. Zhang, and D. Yang, "The practice and inquiries of bidirectional evaluation mechanism of higher mathematics based on process evaluation," Journal of Higher Education, vol. 26, pp. 65-67+71, 2020.

[4] J. Xing and S. Cao, "Exploration on the reform of zoology learning evaluation for biology major in local university," Anhui Agricultural Science Bulletin, vol. 25, pp. 127-128, 2019.

[5] C. He, "The mechanism and pathway for the process evaluation, achievement goal orientation, and learning engagement," Exploration of Higher Education, vol. 11, pp. 36-46, 2020.

[6] Q. Tian, F. Huang, K. Wang, D. Wan, J. Li, and H. Wang, "Land ecological suitability evaluation of nature reserve:with wanfo mountain nature reserve in hunan Province as an example," Journal of Zhejiang University, vol. 46, pp. 201-208, 2020.

[7] M. Chen, Matlab Neural Network Principle and Example Refinement, pp. 278-285, Tsinghua University Press, Beijing, China, 2020.

[8] J. Han, X. Zhang, D. Fan, and Z. Li, "Medical expert diagnosis system based on Improved Discrete Hopfield neural network," Computer \& Digital Engineering, vol. 48, pp. 23622369, 2020.

[9] D. lin, A. V. Vasilakos, Y. Tang, and Y. Yao, "Neural networks for computer-aided diagnosis in medicine: a review," $\mathrm{Neu}$ rocomputing, vol. 216, pp. 700-708, 2016.

[10] H. Xiang, Z. Wang, L. Chen, D. He, and X. Xiong, "The application of discrete Hopfield neural network algorithm in license plate character recognition," China Computer \& Communication, vol. 32, pp. 41-43, 2020.

[11] J. Guo, Study on Water Quality Evaluation and Water Quality Simulation Based on Artificial Neural Network, Chongqing University, Chongqing, China, 2002.

[12] Y. Cui and Q. Zuo, "Comprehensive assessment of water quality based on hopfield network and realization with Matlab," Water Resources Protection, vol. 23, pp. 314-316+32, 2007.

[13] T. Song, D. Tang, and W. Qu, "Project risk analysis model based on discrete Hopfield neural network," Statistics \& Decision, vol. 6, pp. 24-26, 2005.
[14] N. Z. Tabekoueng, I. S. Doubla, N. Tsafack, and K. Jacques, "Window of multistability and its control in a simple 3D Hopfield neural network: application to biomedical image encryption," Neural Computing \& Applications, vol. 33, pp. 21-20, 2020.

[15] J. Quan, Application of Discrete Hopfield Neural Network in Teaching Quality, Chongqing Normal University, Chongqing, China, 2018.

[16] "Dongwen cui application of discrete Hopfield neural network to the assessment of nutritional status in lakes and reservoirs: a case study on 24 lakes and reservoirs in China," Journal of Yangtze River Scientific Research Institute, vol. 29, pp. $10-14+34,2012$.

[17] S. Chen and X. Liu, "Typhoon disaster evaluation model based on discrete Hopfield neural network," Journal of Natural Disasters, vol. 20, pp. 47-52, 2011.

[18] G. Tanaka, T. Yamane, D. Nakano, R. Nakane, and Y. Katayama, "Hopfield-type associative memory with sparse modular networks," Neural Information Processing, vol. 10, pp. 255-262, 2014.

[19] A. Karbasi, H. Amir, A. Salavati et al., "Iterative learning and denoising in convolutional neural associative memories," International Conference on Machine Learning, vol. 19, pp. 445-453, 2011.

[20] M. A. Runnian, L. Sheping, L. Naigong et al., "Stability of discrete Hopfield neural networks with delay," Journal of Systems Engineering and Electronics, vol. 16, pp. 937-940, 2012.

[21] Y. Ma, B. long, and C. Hu, "Construction of evaluation model of college students' curriculum learning effect based on grey clustering," Journal of Mudanjiang Normal University, vol. 03, pp. 62-66, 2020.

[22] Y. Ma and C. Hu, "An empirical research on blended teaching based on mobile phone interaction_- taking "probability theory and mathematical statistics" as an example," Journal of Chaohu University, vol. 21, pp. 140-148, 2019.

[23] T. Ding, G. Rui, and X. Rui, "Competitiveness evaluation of small and medium-sized commercial banks in China based on Entropy TOPSIS: taking 12 joint-stock commercial banks as examples," Finance Theory and Teaching, vol. 6, pp. 14-18, 2015.

[24] J. Zhang and Yi-Z. Jiang, "A study on mental health assessments of college students based on triangular fuzzy function and entropy weight method," Mathematical Problems in Engineering, vol. 2021, Article ID 6659990, 8 pages, 2021. 